\title{
Awareness towards Industry 4.0: Key Enablers and Applications for Internet of Things and Big Data
}

\author{
Myrna Flores ${ }^{1,2}$, Doroteja Maklin², Matic Golob², \\ Ahmed Al-Ashaab ${ }^{3}$, Christopher Tucci ${ }^{1}$ \\ ${ }^{1}$ École Polytechnique Fédérale de Lausanne, College of Management, \\ Odyssea Building, 1015 Lausanne, Switzerland \\ ${ }^{2}$ Lean Analytics Association, Via Colombei 22, 6914 Carona, Switzerland \\ 3 Cranfield University, Building 50, Cranfield, Bedfordshire MK43 0AL, UK \\ \{Myrna.Flores, Christopher.Tucci\}@epfl.ch \\ \{Doroteja.Maklin, Matic.Golob\}@lean-analytics.org \\ Ahmed Al-Ashaab, a.al-ashaab@cranfield.ac.uk
}

\begin{abstract}
The fourth Industrial revolution promises to increase productivity, flexibility and automation of internal business processes integrating value chains and supporting companies to design and offer novel services based on the availability of data enabled by different technologies. As a result, companies are investing great efforts to understand in which way Industry 4.0 technologies could be deployed to leverage their current operations and deliver a more competitive value proposition to existing and new customers. In this context, the objectives of this paper are: 1) to provide the findings from a research project which aimed to capture the awareness from companies about Industry $4.0,2)$ identify which are the key enablers for the successful implementation of Internet of Things (IoT) and Big Data and 3) propose further suggestions about research needed to facilitate the development Collaborative Networks towards Industry 4.0
\end{abstract}

Keywords: Industry 4.0, Internet of Things, Big Data, Survey, Collaborative Networks

\section{Introduction}

The fourth Industrial revolution, also referred to as Industry 4.0, follows previous industrial revolutions which occurred from the 18th century to date. Norbury (2015) and Gilchrist (2016) highlighted certain challenges associated with the three previous revolutions, such as: 1) An increase in complex products; 2) Shorter innovation cycles; 3) Volatile markets and 4) The incapability of human efforts to handle the complexity of present industrial processes and systems.

The term "Industry 4.0" was coined in Germany at the Hannover Messe in 2011 and since then it has become more and more popular; nevertheless, for several, it still remains a buzzword. It comprises several technologies as Internet of Things (IoT), Big Data, Artificial Intelligence, Virtual Reality, 3D Printing, Cyber Security to name 
a few. Their application targets the improvement of internal operational efficiencies and to create new business models offering new data driven services focusing on providing novel customer experiences. Many consulting companies offer their services to support firms applying these latter enabling technologies for what many refer to as "Digital Transformation".

Although there has been an explosion of interest about Industry 4.0 in the last years, still most companies are at the very beginning of their digital transformation journeys. In this context, the aim of this research was to understand the level of awareness in companies about its benefits and business impact and which do they consider are the main implementation enablers for Internet of Things (IoT) and Big Data. The research project followed a structured research methodology as shown in Table 1.

Table 1. Research Methodology

\begin{tabular}{|l|l|}
\hline Identify & Define the research questions and unit of analysis \\
\hline Learn & Conduct a state-of-the-art literature review \\
\hline Explore & Develop a structured online survey and collect data \\
\hline Analyze & Analyze the survey results \\
\hline Diffuse & Develop research publications and whitepapers \\
\hline
\end{tabular}

In the first phase, the research questions were defined as follows:

1) How do companies envision and understand Industry 4.0?

2) Which are the main enablers to implement IoT and Big Data?

During the Learn phase, a literature review was carried out and the offers of topranked consulting companies were searched to have a better understanding of their services towards Industry 4.0. In the Explore phase, a survey was designed and conducted to obtain the trends, challenges, potential applications and enablers related to Industry 4.0. Figure 1 shows some of the companies that participated in the survey. In the Analyze phase data was examined and in the diffuse phase a detailed report with all the findings was distributed to companies together with scientific publications.

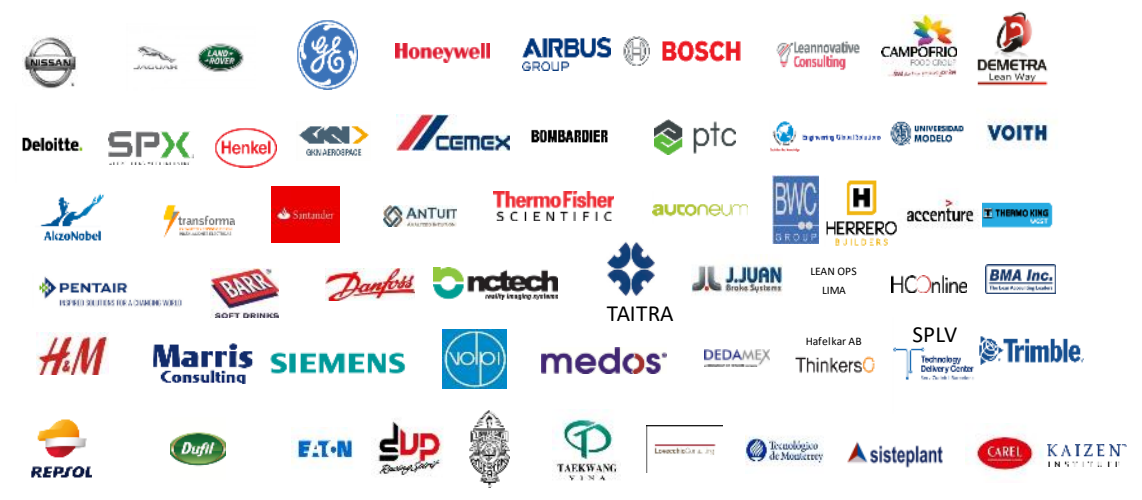

Fig. 1. Some of the participating companies in the survey (Aug to Sept 2017) 


\section{Internet of Things and Big Data}

\subsection{Internet of Things}

A combination of two words, "internet" and "things", which are the building blocks that make up the phenomenon called the Internet of Things (IoT). The "things" aspect was well-captured by Chaouchi, et al., (2013): "things or objects are described as a set of atoms; the atom is the smallest object in the Internet of Things". Some examples of items that can be connected to this are: Buildings, Machines, Industrial Plants, Assets, Vehicles, Transport Units, Containers, Devices, People, and Animals.

The IoT can be defined as the extension of the internet of physical things in such a way that sharing, processing and utilizing data is possible at the same time as interaction with human beings and the virtual world is, with value creation being the end product (Atzori et al., 2010; Khodadadi, et al., 2016).

The Internet of Things consists of four important components: 1) Connectivity: RFID technology and Wireless Sensor Networks (WSNs) appeared in $100 \%$ of the literature that was reviewed; 2) The middleware which acts as a platform through which heterogeneous devices can communicate with each other; 3) Cloud computing which is an important factor ensuring real-time access to and storage of big data generated between devices; and, 4) Data analysis, since a large amount of the data generated will be analyzed.

\subsection{Big Data}

On the other hand, the term Big Data (BD) has become a real buzzword even though it is not a new concept (Harvey, 2012). Big data refers to large data sets that are impossible to manage and process using traditional data management tools due to their volume and speed of creation. Valuable information and in-sights are obtained when big data are collected and analyzed (Akoka, Comyn-Wattiau and Laoufi, 2017).

Gartner (2012), Kwon and Sim (2013) and McAfee and Brynjolfsson (2012) defined Big Data in terms of 3 Vs: a) Volume, referring to the massive amount of data that utilizes huge storage; b) Velocity, representing the high frequency or speed at which data are created and transferred; c) Variety, as data comes from a large variety of different sources, dimensions and formats of data. In other words, big data can be structured or unstructured.

Some authors/practitioners went beyond this definition by adding a fourth $\mathrm{V}$, which stands for Value, to point out the importance of obtaining economic benefits from data (IDC, 2012; Oracle, 2012; Forrester, 2012). Furthermore, White (2012) introduced a fifth $\mathrm{V}$, which stands for Veracity, to emphasize the importance of quality data and the reliability of the sources of data.

On the other hand, Big Data Analytics (BDA) use advanced techniques to obtain useful patterns/insights from an enormous amount of data (Matsunaga, Brancher and Busto, 2015). 


\section{Survey and Findings}

The survey designed for this research consisted of 27 questions distributed in four sections: a) Awareness about Industry 4.0, b) The Internet of Things, c) Enabling technologies, and d) Talent. It was sent by email to 2500 companies and it was intensively promoted in Social Media (LinkedIn, Facebook and Tweeter).

In total 76 individuals located in 25 countries and working in a variety sectors provided a response. The distribution of responses per country, also shown in figure 2, was as follows: United Kingdom (16), Spain (12), Mexico (8), France (5), Switzerland (4), Italy (4), USA (4), Sweden (2), India (2), Slovenia (2), Taiwan (1), Belgium (1), Colombia (1), Hungary (1), Serbia (1), Turkey (1), Germany (1), Vietnam(1), Brazil (1), Latvia(1), The Netherlands (1), Nigeria (1), Australia (1), Portugal (1) and 3 were unknown. Figure 3 shows the different sectors.

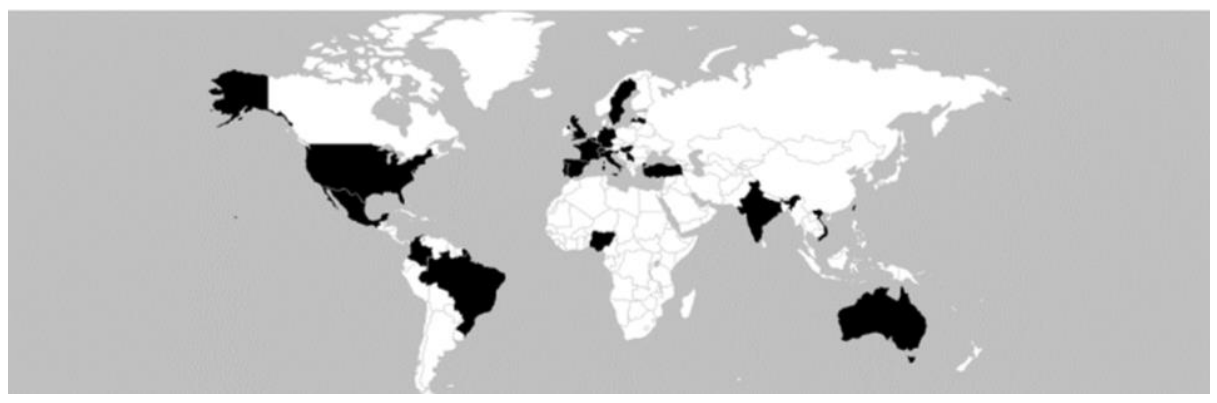

Fig. 2. Countries represented in the research $(\mathrm{N}=76)$

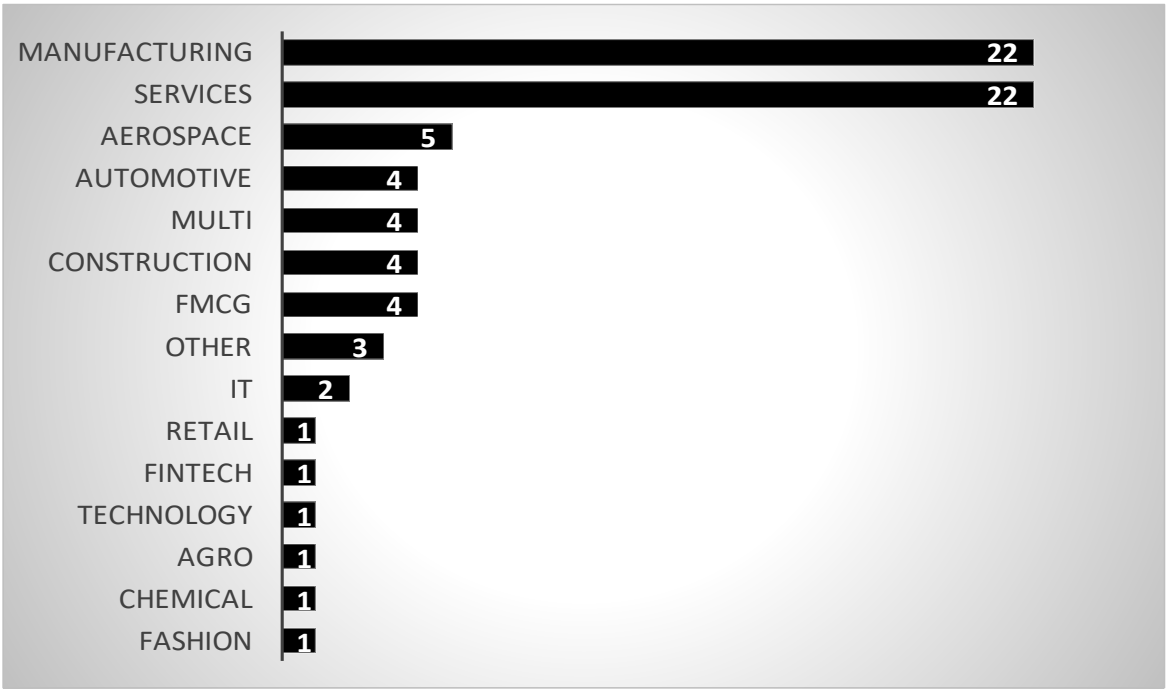

Fig. 3. Number of responses per industrial sector $(\mathrm{N}=76)$ 
The first question addressed the definition of Industry 4.0. The proposed definition was:

"The next industrial revolution involves the integration of the physical world and the digital world and it is driven by the four disruptions below:

1. The impressive rise in data volumes, computational power and connectivity

2. The emergence of analytics and business-intelligence capabilities

3. New forms of human-machine interaction such as touch interfaces and augmentedreality systems

4. Improvements in transferring digital instructions to the physical world, such as advanced robotics and 3-D printing".

The survey results observed in Figure 4 show that $65 \%$ of the respondents agreed with the definition mentioned above. Another 20\% agree with the definition but would add further details, including AI decision-making and the cultural transformation required and $15 \%$ either do not have an opinion or disagree.
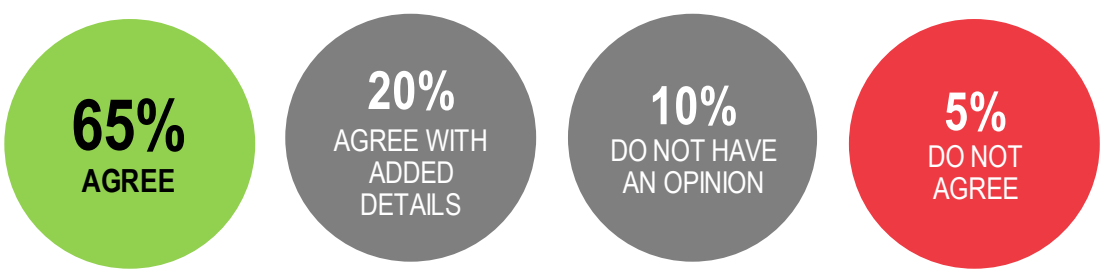

Fig. 4. Opinion about the Industry 4.0 definition $(\mathrm{N}=71)$

In terms of implementation strategy and commitment, as observed in figure 5, only $17 \%$ of the companies already have a fully implemented strategy.

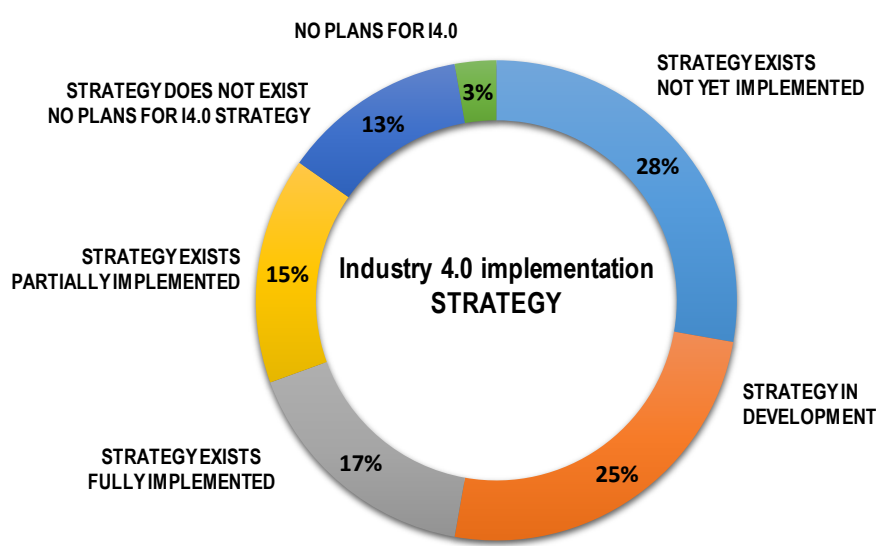

Fig. 5. Current status of an Industry 4.0 Implementation Strategy $(\mathrm{N}=72)$ 


\subsection{Key Enablers and Applications for Internet of Things (IoT)}

a) Have business focus: An increase in efficiency is considered as the main driver for companies to implement the IoT in their processes (57\%), followed by predictions for cost savings (47\%) which would result from its implementation. $45 \%$ of the respondents state that decision making is optimized when using the data gathered and analyzed, while $43 \%$ support that the flexibility of the processes is increased.

c) Define a leading role: $47 \%$ do not have the role of Chief IoT Officer in their organigram.

b) Be clear on the industrial application: The top 3 applications of the IoT are: $63 \%$ in the production process to support the real-time process control, $47 \%$ to gather data and make informed decisions on predictive maintenance and $43 \%$ to monitor and control machines. Interestingly, the activities related to develop new services is still low. Figure 6 consolidates the results about the different applications.

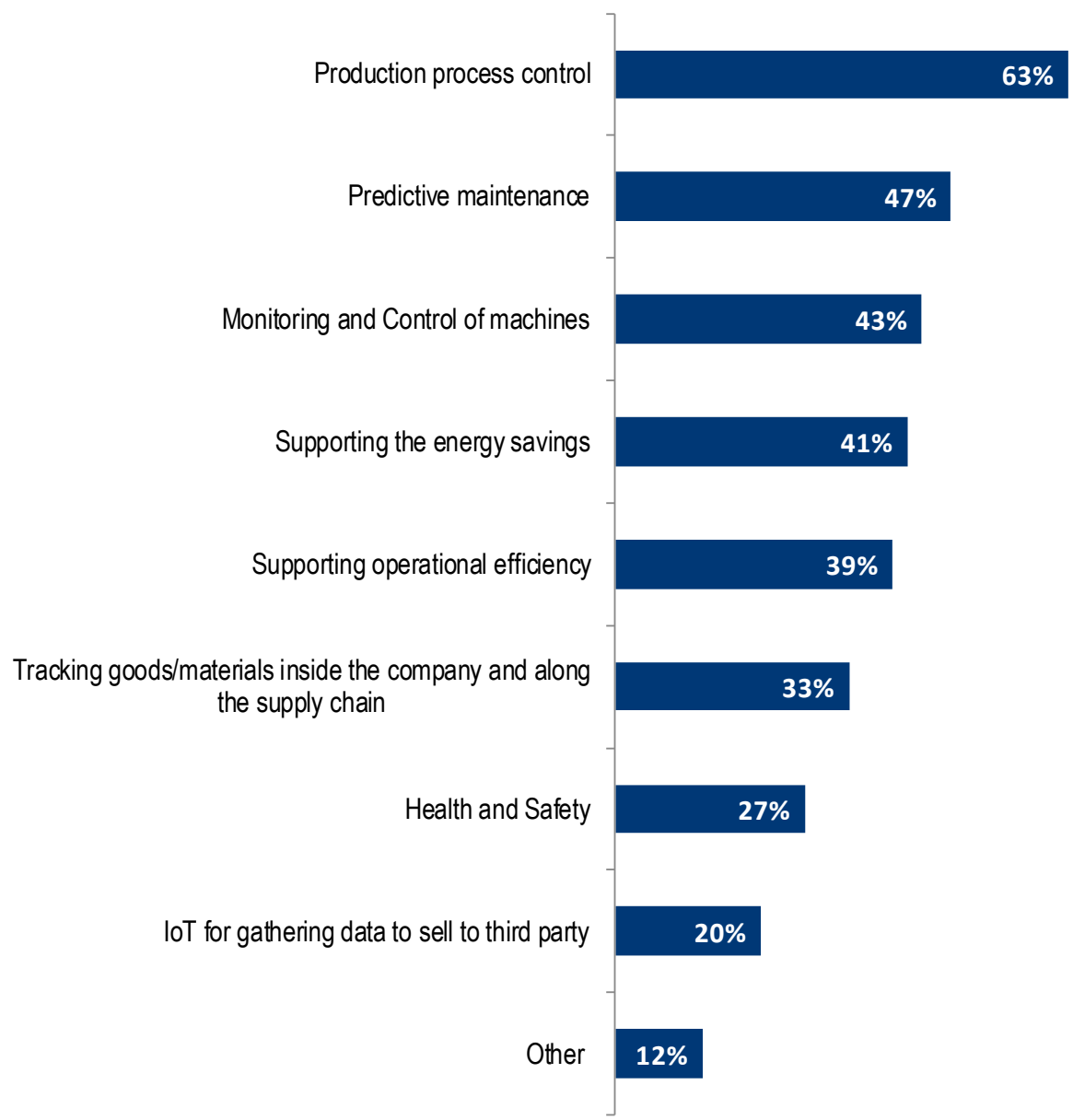

Fig. 6. Main industrial Applications for Internet of Things (IoT) (N=72) 


\subsection{Key Enabler and Applications for Big Data}

According to the analysis, the major enabler for big data are the employees' mindset and skills. Figure 7 consolidates the most relevant skills identified in this research. The majority of the respondents built Data Analytics knowledge internally, either by educating existing employees or hiring talents. The position of internal data scientist is present in $57 \%$ of the organizations and $18 \%$ of the organizations still outsources the data analysis task due to the lack of talent.

\section{Data Analytics (for data wrangling)}

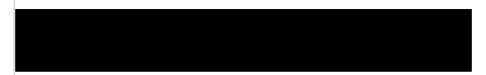

$55 \%$

Service Analytics (for using visual analytics and self-service analytics to analyze data and produce results for management)

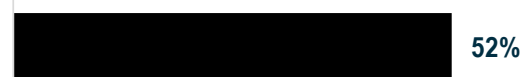

Data Science (for mining and modeling)

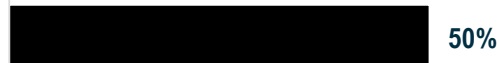

Data Engineering (for data required to support the large-scale production of data)

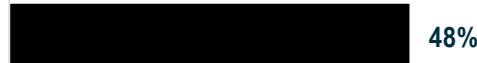

Analytical Solution Architects and Engineers (to produce analytics packages consisting of models, treatments and reports)

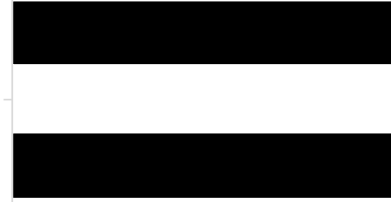

$48 \%$

Cognitive/Decision Science (for determining what solutions decision-makers need to reach decisions)

Programming (to develop prototype capabilities when it comes to profiling, analytics and decision support systems and tools)

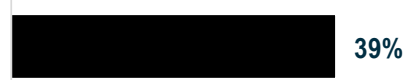

Fig. 7. Skills required to support big data analytics functions $(\mathrm{N}=73)$

In terms of applications, Big Data is seen as a supporting technology enabling optimized decision making (55\%) and helping to increase efficiency $(50 \%)$ and productivity $(43 \%)$. The survey respondents report that Big data is most often used to enable predictive maintenance $(50 \%)$, monitor production processes $(43 \%)$ in real and near real time and to perform performance measurements $(43 \%)$. Big data analytics is also used as a tool to capture and identify customer requirements through marketing $(30 \%)$ as well as for the supply chain integration and traceability of goods in and out of the company in $27 \%$ of the cases. Only $20 \%$ of the respondents use big data to support marketing for dynamic pricing and marketing to explore new markets. In $64 \%$ of the responses, Big Data implementation was carried out by internal teams; $23 \%$ hired external consultants. 


\section{The Creation of Collaborative Networks Towards Industry 4.0}

Industry 4.0 is mainly characterized by an increasing digitalization and interconnection of manufacturing systems, products, value chains, and business models which require a convergence of different technologies. Additionally, these latter systems will also need to interface with humans, in particular employees and customers with different skills and demands. Considering that most companies still do not count with the vital expertise to define a strategy and integrate the different Industry 4.0 technologies on their own, one critical enabler for their successful deployment is the creation of collaborative networks or ecosystems with key knowledgeable partners to speed the implementation.

This implies that close collaboration will be necessary, especially for those companies that have no previous experience whatsoever or a low maturity level implementing Industry 4.0. Six dimensions have been proposed to explain the characteristics of the interconnection between the physical and the virtual / cyber worlds (Camarinha, Fornasiero and Afsarmanesh, 2017):

1) Vertical integration or networking of smart production systems

2) Horizontal integration through global value chains

3) Through-engineering across the value chain

4) Acceleration of manufacturing

5) Digitalization of products and services and

6) New business models and customer access

As challenging as it is to implement Industry 4.0 technologies, it will be also challenging for companies to build new collaborative networks to foster their successful application. Therefore, further research to enable the creation of Collaborative Networks $(\mathrm{CN})$ towards Industry 4.0 is required. Some suggested research questions are:

a. Which are the drivers, challenges, risks, frameworks, processes and business rules required to enable the successful creation of Collaborative Networks $(\mathrm{CN})$ for each of the different proposed six dimensions proposed by Camarinha, Fornasiero and Afsarmanesh, (2017): towards Industry 4.0?

b. Which guidelines could be proposed to support the search and selection of partners towards a successful creation of $\mathrm{CN}$ for Industry 4.0?

c. Which are the change management approaches to inspire other companies to join collaborative networks? Are there any unsuccessful cases? Which are the root causes for their failure?

d. Which are they key roles required? Will the broker role orchestrating the network be required?

e. How to identify the strategic relationships organizations need to create and which collaborative networks are already available for them to join?

f. What factors could hinder the raise and evolution of collaborative networks to co-create new digital services?

g. Which soft and hard skills are required by employees to improve their collaborative culture to co-develop novel solutions towards Industry 4.0? 


\section{Conclusions}

This paper presents the insights gained through literature review and a survey answered by 76 practitioners from different industrial sectors in 25 countries. The findings revealed that there is a good level of awareness about Industry 4.0 among the participating companies. Only 10\% reported they are not aware of the topic. The rest of them confirmed to have an understanding of the definition and the benefits Industry 4.0 brings.

Participants agreed that Industry 4.0 technologies first demand a business case, which should be periodically reviewed. There is a latent and confirmed need for new skills and workers have to be trained to be prepared for this revolutionary change. Practitioners recommended an evaluation of its impact on the organization, the training, new talent acquisition, the culture and the processes change requirements. These latter changes should be kept in mind when planning the transformation in order to gain the expected benefits.

Last but not least, as most companies do not count with the vital expertise to define and deploy a strategy integrating the different Industry 4.0 technologies on their own, it is expected a fast emergence of new collaborative networks. Therefore, further research is required to enable organizations envisioning such digital transformation. This paper includes a list of key research questions that need to be addressed to support organizations to be successful during their Industry 4.0 journeys.

Acknowledgments. The authors thank Angelo Parentini and Oluwaseyi Omoloso, two master degree students at Cranfield University for their valuable contribution. 


\section{References}

1. Akoka, J., Comyn-Wattiau, I. and Laoufi, N. (2017). Research on Big Data - A systematic mapping study. Computer Standards \& Interfaces, 54, pp.105-115.

2. BcG. (2017). Sprinting to Value in Industry 4.0. [online] Slideshare.net. Available at: https://www.slideshare.net/TheBostonConsultingGroup/sprinting-to-value-inindustry-40 [Accessed 4 Jul. 2017].

3. Borgia, E., (2014). The Internet of Things vision- Key features, applications and open issues. Computer Communications, Volume 54, pp. 1-31.

4. Camarinha-Matos L.M., Fornasiero R., Afsarmanesh H. (2017) Collaborative Networks as a Core Enabler of Industry 4.0. In: Collaboration in a Data-Rich World. PRO-VE 2017. IFIP Advances in Information and Communication Technology, vol 506, pp 3-17. Springer, DOI: 10.1007/978-3-319-65151-4_1

5. Chaouchi, H., Bourgeau, T. \& Kirci, P., (2013). Internet of Things: From Real to Virtual World. In: Next-Generation Wireless Technologies, London: Springer, pp. 161-188.

6. Forrester, (2012). The Big Deal About Big Data For Customer Engagement Business: Leaders Must Lead Big Data Initiatives To Derive Value. Available at http://www.forrester.com/ [Accessed 28 May 2017].

7. Gartner, (2012). Big Data. Available at: https://research.gartner.com/definitionwhatis- bigdata?resId=3002918\&srcId=1-8163325102. [Accessed 28 May 2017].

8. Gilchrist, A., (2016). Industry 4.0 : the industrial internet of things. Apress.

9. Harvey, C. (2016). 50 Top Open Source Tools for Big Data. Available at: http://www.datamation.com [Accessed 02 June 2017].

10. IDC, (2017). Data Age 2025: The Evolution of Data to Life-Critical. Don't Focus on Big Data; Focus on the Data That's Big. Available at: http://www.idc.com. [Accessed 01 June 2017].

11. Khodadadi, F., Dastjerdi, A. V. \& Buyya, R., (2016). Internet of Things: An Overview. In: Internet of Things: principles and paradigms. s.l: Elsevier, pp. 3- 23.

12. Kwon, O. and Sim, J., (2013). Effects of data set features on the performances of classification algorithms. Expert Systems with Applications, 40(5), pp.1847-1857.

13. Matsunaga, F.T, Brancher, J.D. and Busto, R.M., (2015). Data mining techniques and tasks for multidisciplinary applications: a systematic review, Revista Eletrôn. Argentina-Brasil Tecnol. Inform. Comun. 1 (2).

14. McAfee, A., Brynjolfsson, E. (2012). Big data: the management revolution. Harv. Bus. Rev. October,61-68.

15. Norbury, A., (2015). Industry 4.0 - Vision to Reality. Retrieved from https://ukmanufacturing2015.eng.cam.ac.uk/proceedings/Industry4.0AN10715.pdf

16. Omoloso, O., (2017). Internet of Things (IoT) towards Industry 4.0. Unpublished master's thesis, Cranfield University, UK.

17. Parentini, A., (2017). Big Data and Analytics. Unpublished master's thesis, Cranfield University, UK.

18. PwC, (2017). Industry 4.0: UK and global companies to invest over $\$$ US 900 billion per year to become truly digital enterprises - Press room. Available at: http://pwc.blogs.com/ [Accessed 11 Jul. 2017].

19. White, M., (2012). Digital workplaces: vision and reality. Bus. Inf. Rev. 29 (4), 205-214. 